\title{
Six Sigma, Sustainability, and IT Management: A Research Review and Discussion of Future Directions
}

\author{
Manal Alduraibi \\ Purdue University \\ maldurai@purdue.edu \\ Timothy A Winders \\ Purdue University \\ winders@pnw.edu \\ Chad Laux, PhD, CSSBB, CSTM \\ Purdue University \\ claux@purdue.edu
}

\begin{abstract}
Purpose- Six Sigma is based upon quality improvement by finding the root cause and refining processes to the precision of process outcomes. The purpose of this research was to conduct a systematic literature review (SLR) to explore the Six Sigma techniques and information technology (IT) management concepts to identify the IT management principle's impact on the sustainability of Six Sigma project efforts and identify the gaps that are essential to be addressed through further research. This research also discusses the principles of IT management upon the influence on Six Sigma projects, and subsequent contribution to organizational economic sustainability. An effective IT infrastructure including communication, data warehousing, and software maximizes the organization's knowledge for management and allowing products and services to be delivered with enhanced quality. Thus, in the absence of that cooperation, Six Sigma projects may be unsustainable.

Design/methodology/approach- Literature published on Six Sigma, sustainability, and related IT management was investigated. The peer-reviewed journal articles were retrieved from different management science publishers, including Emerald, Elsevier, Science Direct, and Springer Link by using the search terms: Six Sigma, sustainability, and related IT management and their combinations. A content analysis was also adopted to analyze the relationship of IT management principles, Six Sigma applications, and sustainability in small-medium organizations.

Findings- Two major themes were developed from the data analysis and coding process. First: effects of Six Sigma on organizational sustainability. Second: effects of IT principles on organizational sustainability.
\end{abstract}

Keywords- Six Sigma, Sustainability, IT Management, IT Infrastructure, Organizational Sustainability 


\section{$8^{\text {th }}$ INTERNATIONAL CONFERENCE ON LEAN SIX SIGMA}

\section{Introduction}

Six Sigma utilizes various tools that rely on data collection to develop cost-cutting and variationreducing solutions. As a result, IT management concepts are critical in supplying the appropriate tools, hardware, and data to implement the Six Sigma project. Thus, this paper aims to highlight the impacts of information technology principles and Six Sigma tools and provide a descriptive response to the research question: How do IT principles impact Six Sigma projects and contribute to an organizational sustainability?

\section{Literature Review}

This literature review includes the paper that explore the role of Six Sigma and IT management on the organizational sustainability. The first section discusses the Six Sigma implementations and tools as a common method in different organizations. The second section reviews the role of IT management principles and its impact on the success of business projects in general and on the success of Six Sigma projects in particular. Finally, the third section describes how Six Sigma contributes to achieve the organizational sustainability.

\section{Six Sigma}

Six Sigma is an effective approach that is commonly used in different organizations, it can be applied in different aspects to allow organizations to achieve needed outcomes. Six Sigma's methodology provides quality improvements in a process and increases the bottom-line profit (Hsieh and Manduca, 2007). From a business perspective, Six Sigma has been defined as a business improvement strategy that is used to increase business profitability, reduce costs of poor quality, and improve the effectiveness and efficiency of all operations to meet customers' needs and expectations (Antony and Banuelas, 2002). The first introduction of the Six Sigma concept in the industry was developed in 1986 by Bill Smith, a senior engineer of Motorola's Communication Division, as he was trying to solve problems that are related to warranty claims. Six Sigma utilizes statistical tools in order to identify a particular factor that matters the most for enhancing the quality of a process, and creating bottom-line results (Hsieh and Manduca, 2007). De Mast (2006) discusses the competencies that a Six Sigma project can bring to an organization, such as discipline, effective problem solving, and good decision-making behavior that could lead to competitive advantages when they are integrated within a company's strategy.

\section{IT Management and Six Sigma}

Information Technology management plays a significant role in today's corporate world especially in the business communication, transaction processing, and decision-making systems (Chan, 2000; Dewett and Jones, 2001). IT management is a discipline that refers to IT operations and activities within the organization. People refer to the combination of hardware, software, database, and networks of the organizational system as IT infrastructure, which serves the essential business needs and makes the daily operations more efficient (Boh and Yellin, 2006). Hsieh, Lin and Manduca (2007) describe information technology as the anatomy of a project. Tsironis and Psychogios (2016) state that IT management support including tools and techniques are essential in the proper application of Six Sigma project and its success. "For effectiveness, adoption and internalization of Six Sigma throughout an organization, it would be highly advisable to ultimately 


\section{$8^{\text {th }}$ INTERNATIONAL CONFERENCE ON LEAN SIX SIGMA}

evolve Six Sigma competence with IT at the core" (Goh, 2011, p.224). Six Sigma projects mainly include "a very large group of tools that support carrying out the project. Hence, each Six Sigma project team, under the leadership of the project's black belt, is expected to select those tools which provide appropriate support for their project" (Hayen, 2009, p.452), therefore, Six Sigma projects' final results can be fully achieved with the support of the IT department. Hayen (2009) mentions that IT staff typically provide, and support computer based Six Sigma tools that need to be available on the desktop platforms of the Six Sigma team. Hsieh et al. (2007) state that "IS and IT are integral components of the DMAIC process" (p.3).

\section{Six Sigma and Sustainability}

Sustainability is an approach used by companies to measure their value in the future for a period of time that a level of performance is desired to be maintained for. Sustainability is not just a method or a tool; it is the companies' mission to maximize their resources, satisfy their customers, improve the condition of their products or services, maintain their success, and sustain competitive advantage (AlSagheer, 2011). Seow and Hall, (2004) state three phrases which they defined as the pursuits of today's organizations: knowledge management, Six Sigma, and sustainable development. AlSagheer (2011) explores the capability of Six Sigma projects that can drive companies to a great extent of sustainability. The author emphasizes three dimensions of Six Sigma that are necessary to achieve a state of sustainability and continuous improvements: strategic, tactical, and operational dimensions. Cherrafi et al. (2016) present a framework that directs organizations to effectively integrate and implement the Green, Lean and Six Sigma approaches to improve their sustainability performance. Their result showed that Lean Six Sigma and Green assist the organizations to averagely reduce their resources consumption from 20 to $40 \%$ and minimize the cost of energy and mass streams by $7-12 \%$ (Cherrafi et al., 2016). Six Sigma also provides methods, tools, techniques, and procedures to decrease the variance of processes not only to increase the capability of processes (Sujova, Simanova and Marcinekova, 2016). Mahdi and Almsafir (2012) provide an approach for services providing organizations that enable a systematic analysis of Six Sigma in diagnosing the sustainable competitive advantage. Their study also shows that there is a correlation relationship between dimension diagnosis of sustainable competitive advantage and the integration of these dimensions. Seow and Hall (2004) discuss some of the issues that small and medium-sized enterprises need to take into account when considering Six Sigma as an enabler to improve and create new knowledge contribution to sustainable development, such as the degree of the communication with the suppliers and customer. Six Sigma could be used for improving the performance of a business leading to higher profit margins (Goh, 2011). Also, a study done by Antony, Gijo and Childe (2012) shows that implementing Six Sigma methodology could contribute to the financial status of the company. Several international organizations have reported significant benefits as a result of Six Sigma implementations, such as General Electric, Motorola, Honeywell, Bombardier, Sony, J P Morgan, American Express, and so on (Antony, 2006). The intention of using Six Sigma in Motorola was not just achieving Six Sigma quality level rather the focus was on reducing defect rate in the process, which allowed Motorola to save $\$ 2.2$ billions of poor-quality cost (Antony and Banuelas, 2002). Dow Chemicals implemented Six Sigma on a corporate-wide basis in 2000, which achieved its target by the end of 2002 that was $\$ 1.5$ billion in cumulative earnings before interest and taxes (Seow et al., 2004). 


\section{$8^{\text {th }}$ INTERNATIONAL CONFERENCE ON LEAN SIX SIGMA}

\section{Methodology}

A systematic review method was employed to narrow down the literature and to gather a reasonable number of studies. The procedure followed for SLR is adapted from the five key phases presented by (Boland et al., 2014) and shown in Figure 1.

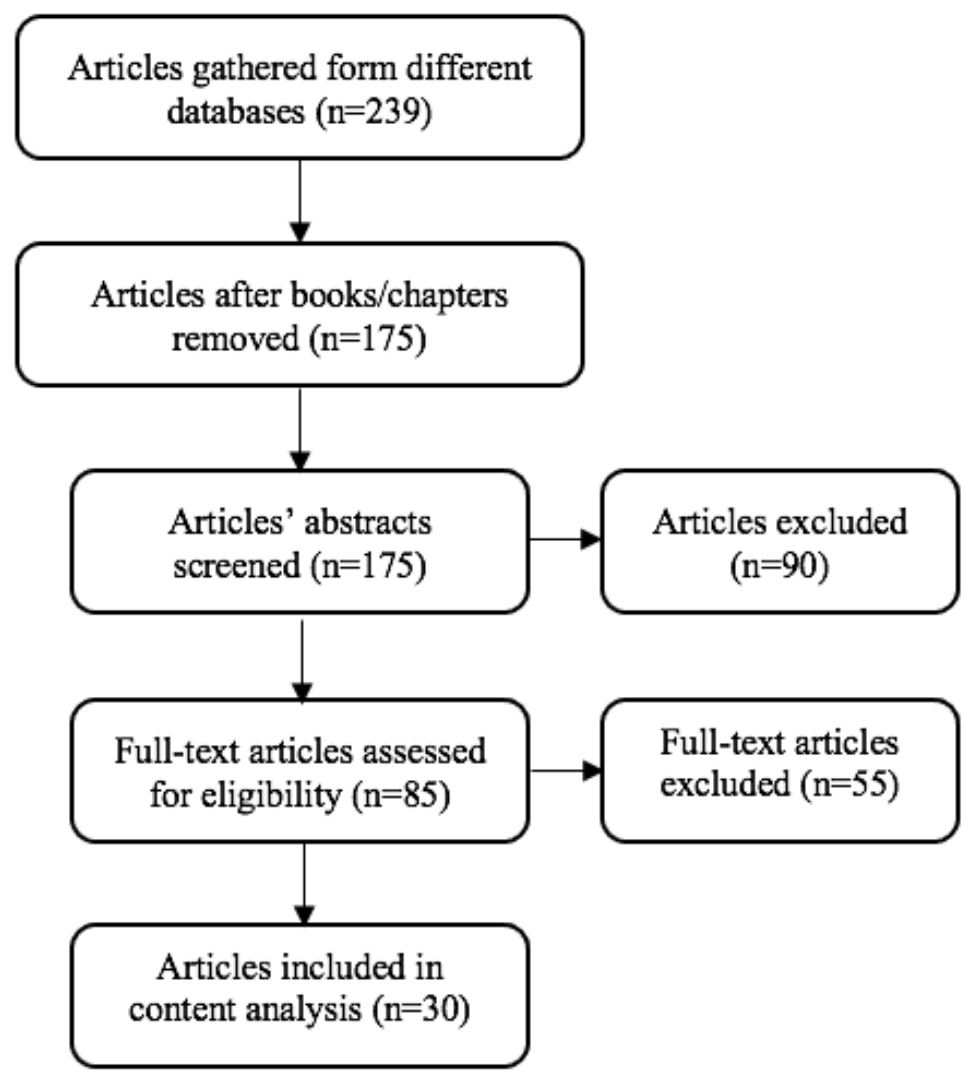

Figure 1. SLR research flow

Peer-reviewed conference and journal papers that were published between 2016-2020 were retrieved from different management science publishers, including Emerald, Elsevier, Science Direct, and Springer Link by using the search terms: Six Sigma, sustainability, and related IT management and their combinations. As shown in Table1 the total search results were 239 papers based on using the keyword search. After deleting books/ chapter books, the total number of articles was reduced to 175 . After that, the authors carefully read the abstract of the 175 articles focusing on the keywords that are identified earlier for this research, and then 85 papers were left by the end of this procedure. Finally, content screening was completed to have a reasonable number of articles and in this final step only 30 papers remained. 


\section{$8^{\text {th }}$ INTERNATIONAL CONFERENCE ON LEAN SIX SIGMA}

Table 1. Using Keyword and Boolean algebra approach for search in Emerald, Elsevier, ScienceDirect and SpringerLink Databases.

\begin{tabular}{|c|c|c|c|c|c}
\hline S\# & Search Terms & Hits & $\begin{array}{c}\text { Extract books/ } \\
\text { chapter books }\end{array}$ & $\begin{array}{c}\text { Go through } \\
\text { abstract }\end{array}$ & Go through content \\
\hline 1 & $\begin{array}{c}\text { "Six Sigma" } \\
\text { AND "IT management" }\end{array}$ & 99 & 62 & 33 & 17 \\
\hline 2 & $\begin{array}{c}\text { "Six Sigma" AND } \\
\text { "Economic } \\
\text { Sustainability" }\end{array}$ & 140 & 113 & 52 & 13 \\
\hline
\end{tabular}

A content analysis approach was followed to analyze the 30 articles we have from the previous method. The aim of conducting a content analysis is to identify themes and show the association between the main concepts (Huff, 1990; Weber, 1990). The remaining 30 articles were imported in NVivo 12 software for content analysis, which is considered as one of the dominant tools that visualize and analyze qualitative data (Bazeley and Jackson, 2013). Using this software allows authors to identify themes and helps them to synthesize results from the imported resources. (Caldera et al., 2017; Thomas and Harden, 2008). The relevant data from the literature was coded under nodes and sub-nodes. For inter-reliability, two of the authors coded the same 7 random articles by using specific words that were put in different groups in the coding book, which the authors had identified before starting the analysis phase. The Kappa Value was greater than 0.6 among the coders.

\section{Findings and Analysis}

Two major themes were developed from the data analysis and coding process. First, the effects of Six Sigma on organizational sustainability. Six Sigma tools illustrated in Figure 2 can be used to assist companies to reduce process variation, enhance performance, and achieve competitive advantages through utilizing powerful and practical tools and techniques. Second, the effects of IT principles on organizational sustainability. IT management has a significant role in shaping the strategic agenda and guaranteeing the IT's ability to accomplish the business's goals. It also provides the departments with new technology and all IT principles illustrated in Figure 2 that are needed to move toward organizational sustainability. 


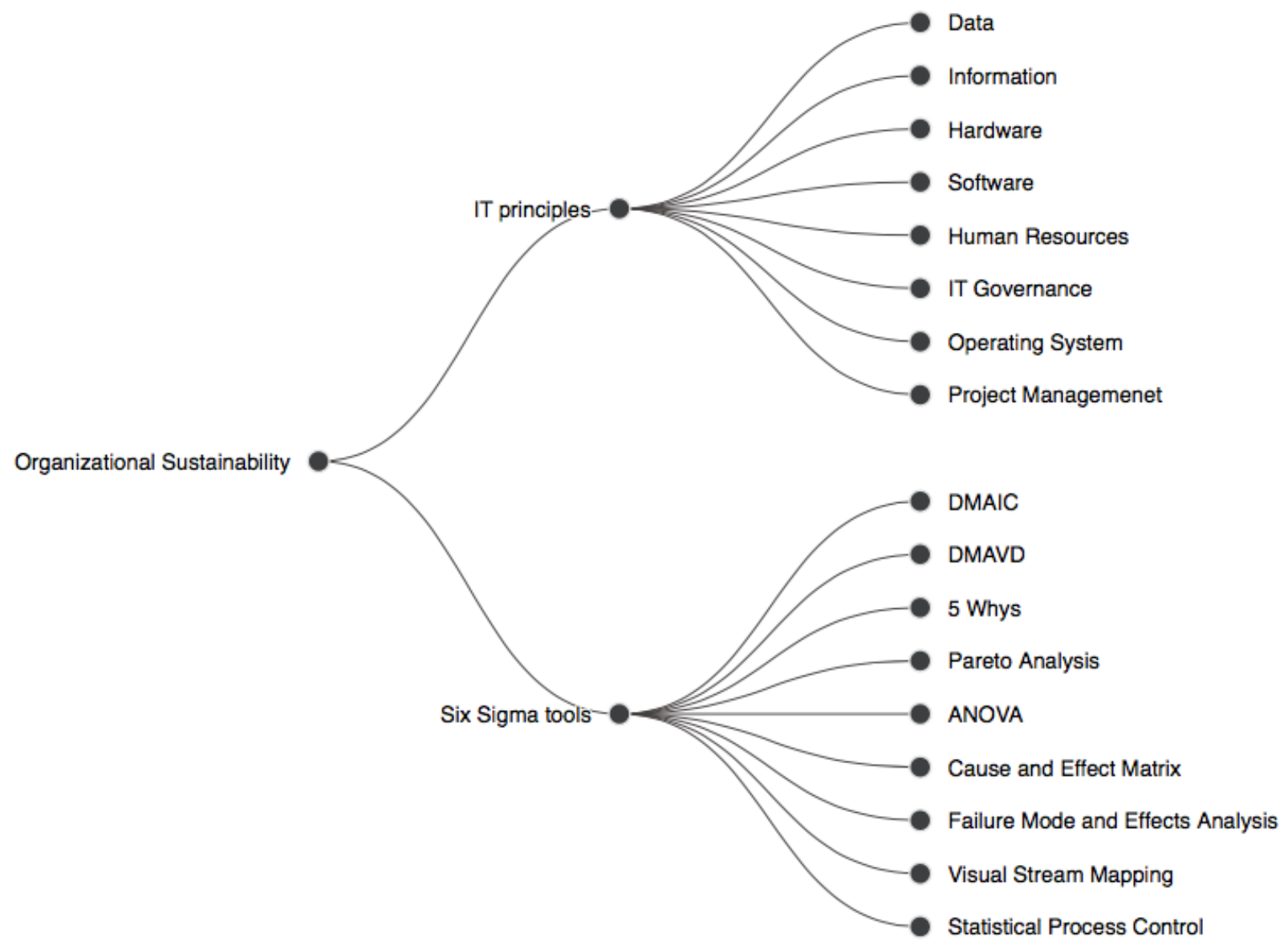

Figure 2. Factors that could contribute to organizational sustainability

First theme: Effects of Six Sigma on an Organizational Sustainability

Six Sigma principles and sustainability studies have become popular in research. The SLR documents the impact of Six Sigma practices and how they could contribute to organizational sustainability (de Freitas, Costa and Ferraz, 2017; Awan, Kraslawski and Huiskonen, 2018; Erdil, Aktas and Arani, 2018; Prasad, Baltov, Rao and Lanka, 2020; Vinodh and Asokan, 2020) through reduction of wastes and reducing the defective parts. By using content analysis for the SLR, we collected all of the Six Sigma tools that mentioned in the articles including: DMAIC, DMADV, 5 whys, Pareto Analysis, cause and effect matrix, Visual Stream Mapping, ANOVA, statistical process control (SPC), and failure mode and effects analysis (FMEA) (Cherrafi, Elfezazi, Chiarini, Mokhlis and Benhida, 2016; Caldera, Desha and Dawes, 2017; Sajan, Shalij and Ramesh, 2017; Erdil, Aktas and Arani, 2018; Kobus, Westner, Strahringer and Strode, 2018; Bhattacharya, Nand and Castka, 2019). However, among these tools, Erdil, Aktas and Arani (2018) state that "Most Six Sigma implementations follow the DMAIC" which assists in activities improvement as well as in performance. Table 2 below shows the finding from the SLR that represents the role of Six Sigma implementation towards organizational sustainability. 


\section{$8^{\text {th }}$ INTERNATIONAL CONFERENCE ON LEAN SIX SIGMA}

Table 2: Effects of Six Sigma on an organizational sustainability

\begin{abstract}
Systematic Literature
"Six Sigma produces profitability, reduction in indirect cost." (Goyal, Agrawal and Saha, 2019).

"Primarily, Six-Sigma is a problem-solving process that helps to ensure that processes are fully effective. It is an intensive, data-driven approach that focuses on how to eliminate the defects from any process."

(Fayoumi and Loucopoulos, 2016).
\end{abstract}

"Six Sigma has a beneficial effect on the sustainability performance." (Cherrafi et al., 2016).

"Six-Sigma methodology and LCA Techniques have significant potential to contribute toward true sustainability and sustainable development purposes.” (Tasdemir, Gazo and Quesada, 2019).

"Six sigma and quality circles are some of the practices adopted by firms to improve the quality of products." (Rajesh, 2020).

\section{Title of the article}

Quality management for sustainable manufacturing: Moving from number to impact of defects

Conceptual modeling for the design of intelligent and emergent information systems
The integration of lean manufacturing, Six Sigma and sustainability: A literature review and future research directions for developing a specific model.

Sustainability benchmarking tool (SBT): theoretical and conceptual Model proposition of a composite framework.

Sustainability performance predictions in supply chains: grey and rough set theoretical approaches.

\section{Second Theme: Effects of IT Principles on an Organizational Sustainability}

The authors created sub-nodes under IT principles that include data, information, digitalization, hardware, software, network, operating system, project manganese, and IT governance to collect some related information about the role of IT provincials in organizational sustainability. Table 3 shows the finding from the SLR that represents the importance of IT components.

Table 3: Effects of IT principles on an organizational sustainability

\section{Systematic Literature}

"Information technology can facilitate coordination within and between firms by making information processing less costly." (Singh, Baird and Mathiassen, 2018).

"ITG maturity has a significant positive impact on IT performance and firm performance." (Smits and Van Hillegersberg, 2017).

"The technological advancements of the last decade have driven organizations to occasionally invent new business models to stay ahead in the competition race." (AlShathry, 2016)

"To promotes successful outcomes in the innovation process, all organizations need to take three cores into account simultaneously administration, innovation core, and information core." (Ettlie, Tucci and Gianiodis, 2017)

\section{Title of the article}

Collaboration risk Management in ITenabled asymmetric partnerships: Evidence from tele stroke networks

The development of a hard and soft IT governance assessment instrument

Business process management: a maturity assessment of Saudi Arabian organizations

Trust, integrated information technology, and new product success 


\section{$8^{\text {th }}$ INTERNATIONAL CONFERENCE ON LEAN SIX SIGMA}

"IT helps to achieve a continuous flow of information about product process, manufacturing issues, deliveries and delay in production line"... "IT also helps to track the inventory at any point of time to reduce waste and avoid shortage of material for production." (Prasad, Baltov, Rao and Lanka, 2020).

"IS project managers rated the importance of economic sustainability highly." (Yazici, 2020).

"Through the application of the information and communication technologies, the business processes become highest integrated"... "The increased use of information technology can provide an increase in productivity for companies." (Barud, de Oliveira, Gomes, Sanseverino, dos Santos Barcelos and dos Santos, 2021).

"Cooperation between business and IT functions in developing and deploying software robots is beneficial." (Van der Aalst, Bichler and Heinzl, (2018).

"Within organizations technology and thereby the IT department are becoming increasingly important for driving innovation." (Jung and Lehrer, 2017).

"The use of big data derived information improves decision making and business process outputs" ... "big data enables economic improvements, competitive gains, better performance or other incentives" (Brinch, Stentoft and Näslund, 2020).

"Information is useful to help organizations to make better decisions and provide better services." (Tu, Yuan, Archer and Connelly, 2018).

"Digitally-enabled human resource development initiatives, in turn, offer numerous socioeconomic sustainability opportunities such as employee productivity and overall corporate efficiency." (Ghobakhloo, 2020).
Interdependency analysis of lean manufacturing practices in case of Bulgarian SMEs: interpretive structural modeling and interpretive ranking modeling approach An exploratory analysis of the project management and corporate sustainability capabilities for organizational success Lean in information technology departments or companies: identifying publications on the Scopus and Web of Science databases

Robotic process automation

Guidelines for Education in Business and Information Systems Engineering at Tertiary Institutions

Alignment capabilities of big data's value creation in the context of service delivery processes

Strategic value alignment for information security management: A critical success factor analysis.

Industry 4.0, digitization, and opportunities for sustainability

Other factors generated from analyzing the SLR which go under the IT principles and could contribute to positively influence the organization such as, Lean IT which aims to reduce waste develop customer value (Kobus et al., 2018); Project management which strengthens the effects of sustainability efforts, specifically in economic and social sustainability" (Yazici, 2020); Maturities in project stakeholder management which positively contribute to increasing market share, organization's reputation, and customer value " (Yazici, 2020). On the other hand, some authors state that the lack of IT support could lead to challenges in the organization's projects and performances and resulting to negatively could impact the organizational sustainability (Fayoumi and Loucopoulos, 2016; Ettlie, Tucci and Gianiodis, 2017; Erdi, Aktas and Arani, 2018; Belkadi, Cherti and Bahaj, 2018). Alotaibi (2016) highlights in his paper the IT-related issues that could face the business, such as misalignment between business strategies and IT strategies, specifying IT development requirements, etc. 


\section{$8^{\text {th }}$ INTERNATIONAL CONFERENCE ON LEAN SIX SIGMA}

\section{Conclusion and Future Directions}

This research aimed to provide a qualitative Six Sigma and IT management analysis of the past 5 years. In the early stages of this study, we focused on exploring the relationship between IT concepts and Six Sigma tools and how this could lead to project sustainability. However, due to the small number of studies in this domain, we developed other Six Sigma, IT, and Sustainability themes. We undertook a systematic analysis to define the position of Six Sigma instruments and IT management concepts. Following this, we also adopted a content research methodology to study peer-reviewed articles in Six Sigma and IT management and how the convergence of these principles could assist in organizational sustainability.

One of the major challenges of investigating the role of IT management in Six Sigma projects is to navigate the minimal literature to describe the effect of IT management on Six Sigma projects. This science and academic gap attribute to the lack of study in this field. Thus, a study of the role of IT principles in Six Sigma projects is required to close this gap and contribute to the body of knowledge in this area due to its importance. The findings of this research show a minimal focus on the role of IT management, concepts in conducting six sigma programs, considering the important role of IT in organizational sustainability.

\section{Conflict of Interest}

The authors declare no conflict of interest. 


\section{$8^{\text {th }}$ INTERNATIONAL CONFERENCE ON LEAN SIX SIGMA}

\section{References:}

Alotaibi, Y., 2016. Business process modelling challenges and solutions: a literature review. Journal of Intelligent Manufacturing, 27(4), pp.701-723.

AlSagheer, A., 2011. Applying six sigma to achieve enterprise sustainability: preparations and aftermath of six sigma projects. Journal of Business \& Economics Research (JBER), 9(4), pp.51-58.

AlShathry, O., 2016. Business process management: a maturity assessment of Saudi Arabian organizations. Business Process Management Journal.

Antony, J. and Banuelas, R., 2002. Key ingredients for the effective implementation of Six Sigma program. Measuring business excellence.

Antony, J., Gijo, E.V. and Childe, S.J., 2012. Case study in Six Sigma methodology: manufacturing quality improvement and guidance for managers. Production Planning \& Control, 23(8), pp.624-640.

Awan, U., Kraslawski, A. and Huiskonen, J., 2018. Understanding influential factors on implementing social sustainability practices in Manufacturing Firms: An interpretive structural modelling (ISM) analysis. Procedia Manufacturing, 17, pp.1039-1048.

Barud, N.A., de Oliveira, R.A., Gomes, C.F.S., Sanseverino, A.M., dos Santos Barcelos, M.R. and dos Santos, M., 2021. Lean in information technology departments or companies: identifying publications on the Scopus and Web of Science databases. Scientometrics, 126(3), pp.2437-2457.

Bazeley, P. and Jackson, K., 2013. Perspectives: qualitative computing and NVivo. Qualitative data analysis with Nvivo, pp.1-46.

Belkadi, S., Cherti, I. and Bahaj, M., 2018, July. Lean in information technology: Produce the human before the software. In International Conference on Advanced Intelligent Systems for Sustainable Development (pp. 203-213). Springer, Cham.

Bhattacharya, A., Nand, A. and Castka, P., 2019. Lean-green integration and its impact on sustainability performance: A critical review. Journal of Cleaner Production, 236, p.117697.

Boh, W.F. and Yellin, D., 2006. Using enterprise architecture standards in managing information technology. Journal of Management Information Systems, 23(3), pp.163-207.

Boland, J.W., McWilliams, K., Ahmedzai, S.H. and Pockley, A.G., 2014. Effects of opioids on immunologic parameters that are relevant to anti-tumour immune potential in patients with cancer: a systematic literature review. British journal of cancer, 111(5), pp.866-873.

Brinch, M., Stentoft, J. and Näslund, D., 2020. Alignment capabilities of big data's value creation in the context of service delivery processes. Supply Chain Management: An International Journal.

Caldera, H.T.S., Desha, C. and Dawes, L., 2017. Exploring the role of lean thinking in sustainable business practice: A systematic literature review. Journal of cleaner production, 167, pp.1546-1565.

Chan, S.L., 2000. Information technology in business processes. Business Process Management Journal.

Cherrafi, A., Elfezazi, S., Chiarini, A., Mokhlis, A. and Benhida, K., 2016. The integration of lean manufacturing, Six Sigma and sustainability: A literature review and future research directions for developing a specific model. Journal of Cleaner Production, 139, pp.828846. 


\section{$8^{\text {th }}$ INTERNATIONAL CONFERENCE ON LEAN SIX SIGMA}

de Freitas, J.G., Costa, H.G. and Ferraz, F.T., 2017. Impacts of Lean Six Sigma over organizational sustainability: A survey study. Journal of cleaner production, 156, pp.262-275.

De Mast, J., 2006. Six Sigma and competitive advantage. Total Quality Management and Business Excellence, 17(04), pp.455-464.

Dewett, T. and Jones, G.R., 2001. The role of information technology in the organization: a review, model, and assessment. Journal of management, 27(3), pp.313-346.

Erdil, N.O., Aktas, C.B. and Arani, O.M., 2018. Embedding sustainability in lean six sigma efforts. Journal of Cleaner Production, 198, pp.520-529.

Ettlie, J.E., Tucci, C. and Gianiodis, P.T., 2017. Trust, integrated information technology and new product success. European Journal of Innovation Management.

Fayoumi, A. and Loucopoulos, P., 2016. Conceptual modeling for the design of intelligent and emergent information systems. Expert Systems with Applications, 59, pp.174-194.

Ghobakhloo, M., 2020. Industry 4.0, digitization, and opportunities for sustainability. Journal of Cleaner Production, 252, p.119869.

Goh, T.N., 2011. Six Sigma in industry: some observations after twenty-five years. Quality and Reliability Engineering International, 27(2), pp.221-227.

Goyal, A., Agrawal, R. and Saha, C.R., 2019. Quality management for sustainable manufacturing: Moving from number to impact of defects. Journal of Cleaner Production, 241, p.118348.

Hayen, R.L., 2009. SIX SIGMA MEET INFORMATION SYSTEMS.

Hsieh, C.T., Lin, B. and Manduca, B., 2007. Information technology and Six Sigma implementation. Journal of Computer Information Systems, 47(4), pp.1-10.

Huff, A.S. ed., 1990. Mapping strategic thought. John Wiley \& Sons Incorporated.

Jung, R. and Lehrer, C., 2017. Guidelines for education in business and information systems engineering at tertiary institutions. Business \& Information Systems Engineering, 59(3), pp.189-203.

Kobus, J., Westner, M., Strahringer, S. and Strode, D., 2018. Enabling digitization by implementing Lean IT: lessons learned. The TQM Journal.

Mahdi, O.R.A. and Almsafir, M.K., 2012. Diagnosing of sustainable competitive advantage using Six Sigma methodology. International Journal of Business and Management, 7(7), p.94.

Prasad, S., Baltov, M., Rao, N. and Lanka, K., 2020. Interdependency analysis of lean manufacturing practices in case of Bulgarian SMEs: interpretive structural modelling and interpretive ranking modelling approach. International Journal of Lean Six Sigma.

Rajesh, R., 2020. Sustainability performance predictions in supply chains: grey and rough set theoretical approaches. Annals of Operations Research, pp.1-30.

Sajan, M.P., Shalij, P.R. and Ramesh, A., 2017. Lean manufacturing practices in Indian manufacturing SMEs and their effect on sustainability performance. Journal of Manufacturing Technology Management.

Seow, C. and Hall, D., 2004, October. Six sigma as a process enabler and strategic facilitator for knowledge in sustainable development: a SME case study. In 2004 IEEE International Engineering Management Conference (IEEE Cat. No. 04CH37574) (Vol. 3, pp. 11171120). IEEE.

Singh, R., Baird, A. and Mathiassen, L., 2018. Collaboration risk management in IT-enabled asymmetric partnerships: Evidence from telestroke networks. Information and Organization, 28(4), pp.170-191.

Smits, D. and Van Hillegersberg, J., 2017. The development of a hard and soft IT governance assessment instrument. Procedia computer science, 121, pp.47-54. 


\section{$8^{\text {th }}$ INTERNATIONAL CONFERENCE ON LEAN SIX SIGMA}

Sujova, A., Simanova, L. and Marcinekova, K., 2016. Sustainable process performance by application of six sigma concepts: The research study of two industrial cases. Sustainability, 8(3), p.260.

Tasdemir, C., Gazo, R. and Quesada, H.J., 2019. Sustainability benchmarking tool (SBT): theoretical and conceptual model proposition of a composite framework. Environment, Development and Sustainability, pp.1-43.

Thomas, J. and Harden, A., 2008. Methods for the thematic synthesis of qualitative research in systematic reviews. BMC medical research methodology, 8(1), pp.1-10.

Tsironis, L.K. and Psychogios, A.G., 2016. Road towards Lean Six Sigma in service industry: a multi-factor integrated framework. Business Process Management Journal.

Tu, C.Z., Yuan, Y., Archer, N. and Connelly, C.E., 2018. Strategic value alignment for information security management: A critical success factor analysis. Information \& Computer Security.

Van der Aalst, W.M., Bichler, M. and Heinzl, A., 2018. Robotic process automation.

Vinodh, S. and Asokan, P., 2020. Development of structural equation model for Lean Six Sigma system incorporated with sustainability considerations. International Journal of Lean Six Sigma.

Weber, R., 1990. Basis content analysis (2nd ed.). Thousand Oaks, CA: Sage Publications.

Yazici, H.J., 2020. An exploratory analysis of the project management and corporate sustainability capabilities for organizational success. International Journal of Managing Projects in Business. 